\title{
ECONOMICS AND MATHEMATICAL RELATIONSHIP: A CASE STUDY IN UNIVERSITY ECONOMICS COURSE OF NEPAL
}

\author{
Yadav Mani Upadhyaya, PhD*
}

\begin{abstract}
:
In our teaching program and methods, the mathematical approach has a major influence on economics. In this paper, I examined the aforementioned economics and mathematical relationships, taking into account their historical development as well as the experience gained over several years in the Masters in Economics Sciences' economics course. Changes in the initial practices in the classroom entering university have prompted a rethinking of a number of fundamental questions, including: What parameters should be used to determine the most suitable curriculum and teaching approach in a changing environment? What mathematical singularities does economics teaching present? This last question introduces us to the topic we'll be discussing. How much math should be taught in economics classes? Is it important for students to have a strong mathematical foundation before they study economics? For some teachers, economic issues are merely an addendum to the practical portion of the topic, while for others; economic models are the subject's main focus. As a consequence, mathematics in general is now assisting in the analysis of economics. In conclusion, as students study economics, it becomes more difficult for them to study other mathematics topics. Since not all students excel at math, economics is a more difficult subject to study.However, studying algebra, calculus, and logarithms, among other subjects, makes economics more important.
\end{abstract}

Keywords: education, economics and mathematics, relationship, complication, easiness

JEL:

A22, C69

\section{Introduction}

A large number of books have been written about the importance of mathematics in economics. This contentious topic has a significant effect on the teaching of economics for mathematics, in addition to having an impact on the growth of the economy as a social science (Hodgson, 2004). Educators in the eighteenth and nineteenth centuries believed that an economist's education was forged in fundamental subjects (Microeconomics, Macroeconomics, and Statistics), with specialized subjects serving as a supplement to this training and a source of professional knowledge (Debreu, 1986).This approach, mathematics learning and teaching should be viewed primarily as a tool for analyzing fundamental knowledge, with little initial consideration of potential specializations. (Katzner, 2003).

\footnotetext{
* Assistant Professor of Saraswati Multiple Campus (Humanities Faculty: Economics Department), Tribhuvan University, Nepal.
} 
I'd like to put ourselves in the shoes of economists (or an economics teacher) and consider the role of mathematics in economics classes. Is it important to have a strong mathematical background before learning economics fundamentals? or Should each mathematical principle be accompanied by an economic application? or is a student's curiosity piqued by a combined analysis of both disciplines?(Bai, 1997). It is obvious that these and other reflections have a significant influence on the programming and technique of our topics.

In section one of this paper, I examine the students with whom we will be working, attempting to comprehend what it means to move from high school to university. In section 2, I go through some of the features of the mathematical/economic relationships, keeping in mind the context we're looking at. In section 3, I present the findings of a concrete study that I conducted by contrasting a set of problems and questions with an economic content that were posed in midterm or final exams over the previous three academic years with problems and questions with only a mathematical content. Finally, I give some preliminary conclusions.

\section{The Study from Higher Secondary to University}

The transition from demonstrative to demonstrative economics is the most noticeable distinction between high school and university economics organizations in terms of structure. Demonstrations are virtually non-existent in higher secondary school, and any justifications that might occur in class tend only to embellish the teacher's discourse (in the recommendations for university entrance exams, teachers are told that it is enough to quote the theorems justify them graphically). They are easily overlooked by the student (Lawson, 2001).According to the preceding, precise meanings are also unnecessary. Definitions work more to define previously existing objects than to logically create new objects, so an approximation of the meaning would sufficeMcClosky, Katzner,Leamer and Solow, 1991).

In university teaching, on the other hand, evidence becomes the primary source of revenue. Implicitly, it is known that all comments made at university must be justified by the student Anderson, Goft and Tollison, 1986). To explain a theorem's applicability, you must test its hypotheses. You must be able to determine whether or not an object satisfies a set of criteria. Accept the fact that the property depicted in the graphs has no demonstrative value (Bai and Perron, 1998). It is hoped that the student would recognize the significance of the demonstration and, as a result, the importance of defining the terms.

In terms of problem-solving operation, there is a clear preponderance of problems to be solved in secondary school to an important presence of problems to be demonstrated in university, which is consistent with the shift from demonstrative economics to demonstrative economics (Collander, 2005). In line with the preceding, the student's transition from one economic organization to another causes them to move from being a student with little autonomy and little economic responsibility to being a co-responsible for their training process (Bai and Perron, 2003).

Most economics and business students move from a mathematical organization focused primarily on the subject mathematics applied to social sciences to one based on linear algebra and calculus in one and multiple variables (Debreu, 1991). 
Higher secondary school algebra is organized around the concept of solving systems of linear equations and basic linear programming problems. After modeling statement problems, reduction methods or the so-called Gaussian approach are used to solve them, as the analysis of determinants has been abandoned (Hamermesh and Schumidt, 2003). Surprisingly, the algebraic instrument is taught in university classes as though it were well-known. Logic symbols are suddenly required, axioms are introduced, and theorems are justified and demonstrated using the aforementioned axioms and new definitions (Jon, 2004). The study of algebra in college mathematics is so systematic and normal from the beginning that students must easily complete all of their cognitive development stages (Hodrick and Prescott, 2007).

Calculus in higher secondary school, on the other hand, is organized around the study of individual functions, while at university, groups of functions are studied (Sheila, 2003). Geometric intuition sufficed in secondary school, one of the key goals of calculus analysis at the university level is to demonstrate that this intuition is not only inadequate but also misleading. While concrete problems of minimizing costs and maximizing benefits are solved in higher secondary school, integrals are not studied, and therefore there is no global structure that provides an integrative view of all the basic economic functions (Kiyko, 2006).

These antecedents compel us to consider the parameters that should be used to determine the contents and methods of the economics subject that we teach in the first and second semesters of the Masters in Economics, as well as whether we are solely responsible for implementing the changes that we believe are needed. What are its limitations, in any case? We have confined ourselves to studying the relationship between economics and mathematics in the teaching of our subject because the actual changes that are ultimately encountered are minimal. The appearance of new approaches and texts of economics for mathematics invites us, where economic issues are developed in greater depth.

\section{Relationship of Economics and Mathematics}

From the teaching point of view and with different nuances, we think that there are two essential ways of approaching the economic-mathematical relationships:

1) Deepening the study of mathematics to consolidate a base that later allows the study of economic models;

2) Justify each advance in mathematics with its application to a related topic in economics. One way of thinking or another implies different ways of approaching the subject.

The evolution of economics/mathematics relationships will serve as a basis for considering the best teaching method. To do so, we choose a small selection of several measurable facts that will be the focus of our investigation.

First, let's take a look at how economics uses mathematical tools and techniques. This relationship can be divided into three periods: the marginalist era (from 1838 to 1947, when P. Samuelson published the Fundamentals of Economic Analysis), the fixed period (from 1948 to 1959), and the integration period (from 1960 to today) (Neumann, 2004). 
Marginalism, based on infinitesimal calculus logic, establishes the mathematical basis of output, consumption, and general equilibrium theories, despite its limitations. It takes Physics as a starting point, attempting to translate theoretical mechanics principles and formulations into economic language (Lindbeck, 2001).

A new generation of economists emerges around the time of the Newtonian physics crisis and the advent of the theory of relativity, using topology to give economic theory a new formulation. The topological-conjunct approach would be used to prove the equilibrium's existence, while the infinitesimal calculus approach would be used to investigate the equilibrium's stability. The era of Leontief's linear models has arrived (Ekurzel and McMillian, 2001).

From the 1960s to the present, the use of mathematical methods and instruments in economics has expanded to the point that almost all branches of mathematics have entered some area of economics, thus justifying the period's name. Topology, geometry, classical and functional analysis, as well as dynamic equations (differential, difference, partial derivative, and so on) all play a role in economic reasoning. Similarly, recent mathematical advances such as the Theory of Catastrophes, Fuzzy Sets, and fuzzy logic have made inroads in the economy (Samuelson, 1954).

Second, there's the most recent economic analysis. When you compare today's academic journals to those from fifty years ago, you'll notice a significant increase in mathematical language. At all stages, the same can be said of economics books. However, as the relevance of mathematics is recognized in the field of economics, some academic sectors are questioning the teaching of mathematics subjects in Economics and Business (Debreu, 1984).

Finally, there are scientific mathematical economics relationships to consider. The relationships between physics and mathematics were a common thread for the first economists who implemented calculus by mathematizing economic theory. It was hoped that mathematics in general and differential calculus in particular, would help legitimize neoclassical economic theory as a sort of social physics (Goffe and Parks, 1997). The relationship between mathematics and economics, on the other hand, is somewhat different from the relationship between mathematics and physics (Arkhipov, 1999).

The derivative is an example of a subject. Calculating the instantaneous velocity as the limit of the mean velocity in physics is similar to calculating the slope of the tangent as the limit of the slope of the secant in mathematics. This is not the case in economics, where the principle of marginality necessitates a jump from discrete to justifiable continuous in order to fully exploit the infinitesimal calculation's force. Economists such as Samuelson condemn the mathematical assumptions used in neoclassical economic theory for their lack of realism (Grubel and Boland, 1986).It has been criticized that when developing certain models, the reality of economic processes is always forced to follow or conform it to the formal requirements of mathematical analysis. And the definitions of certain mathematical functions and theorems can be used to support the demonstration of such economic outcomes. 


\section{Objectives}

Mathematical phenomena like calculus, algebra, logarithm etc. play an important role in the interpretation and analysis of economics. That is to say, this study helps to further support the study of economics. Its main three objectives are as follows.

- To make economics students feel the need to study mathematics as well.

- To make people feel the need for economics as the study of economics is a holistic study,

- To explain the need of economics, although economics is a single subject in itself, for students it is not only a single subject but also related to other subjects and has a special relationship with mathematics.

\section{Test and Calculation with Methodology}

In recent academic years, we have adapted our teaching programming and methodology to research economic applications of the mathematical concepts established, based on the premises outlined in the two previous parts. To assess the outcome, we looked at a collection of economic problems and questions from the last three academic years' midterm and final exams. We want to look at how students react to a more conventional math problem that doesn't require them to use economic concepts.

The student must now not only understand the mathematical method for solving the exam's exercise, but also perform some mathematical modeling that helps him to pass the economic argument to a known mathematical model that can be used with the resolution techniques discussed in class (Sheila, 2003).

To carry out our study, within the economic topics addressed we differentiate between the economic contents that appear in algebra questions and calculus questions:

1) Economic contents of linear algebra:
a. Systems of Linear Equations: Production problems, IS-LM Model
b. Leontieff Linear Models, Input-Output matrices
c. Markov processes
d. Models of equations in finite differences (Recursive models).

2) Economic contents of differential and integral calculus:
a. Marginalism
b. Elasticity
c. Consumer surplus and producer surplus 
The table 1 shows the percentage of questions eligible with a passing grade out of the total number of questions asked in each test, separating those with mathematical content from those with economic content. We also distinguish between Linear Algebra and Calculus:

Table 1: Calculation of Linear Algebra and Calculus

\begin{tabular}{|c|c|c|}
\hline Subject & Algebra & Calculation \\
\hline Economics & $30.38 \%$ & $49.05 \%$ \\
\hline Math & $45.56 \%$ & $54.64 \%$ \\
\hline
\end{tabular}

Figure 1: Linear Algebra and Calculus

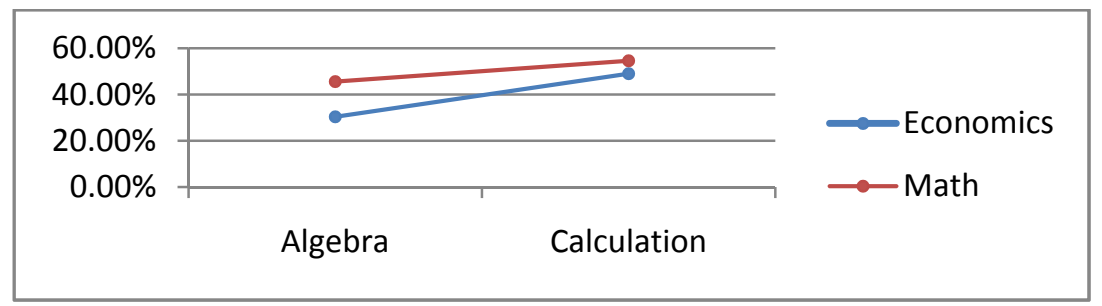

The statistics show that while 45.56 percent of students pass the linear algebra mathematical content questions, just 30.38 percent of students pass the economic content questions, a gap of more than 15 percentage points.

In contrast, we can see that the percentages are much closer in a measure, while the percentage referring to questions with mathematical content remains higher. The data show that, despite paying more attention to the business student's career material, the results of the objective tests are not as encouraging as one would anticipate.

The table 2 shows how many students have left the questions blank or have been scored zero:

Table 2: Calculation of Economics and Math

\begin{tabular}{|c|c|c|}
\hline Subjects & Algebra & Calculation \\
\hline Economics & $31.75 \%$ & $27.79 \%$ \\
\hline Math & $37.04 \%$ & $30.28 \%$ \\
\hline
\end{tabular}

Source: Survey Report

Figure 2: Relation of Economics and Math

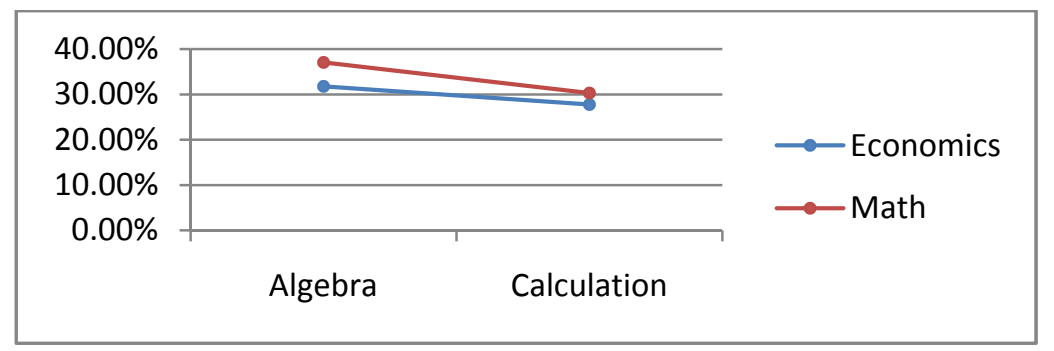


When comparing questions with mathematical content to questions with economic content, we note that the pattern has shifted; now, when the question is of mathematical content, it is more likely to receive a score of zero (or not answered). Students find economic content problems more appealing at first, but they become even more difficult to solve later.

In general, students are more reticent, or show a greater aversion, to the Linear Algebra part than to the Calculus part. We will now focus on a separate analysis of the results obtained in the two types of exams. In the first place, we have considered a collection of questions asked in linear algebra exams and we analyze the average number of students who have obtained the different numerical grades (between 0 and 1.5 points per question). The results have been the table 3 :

Table 3: Average Number of Student

\begin{tabular}{|c|c|c|}
\hline Linear Algebra & \multicolumn{2}{|c|}{ Average number of students achieving the grade } \\
\hline Qualification & Math & Economics \\
\hline 0.00 & 55.67 & 25.75 \\
\hline 0.25 & 8.83 & 26.00 \\
\hline 0.50 & 12.00 & 34.25 \\
\hline 0.75 & 11.67 & 9.25 \\
\hline 1.00 & 12.50 & 7.00 \\
\hline 1.25 & 6.67 & 11.25 \\
\hline 1.50 & 26.17 & 19.75 \\
\hline
\end{tabular}

Source: Survey Report

Figure 3: Graphical Presentation of Grade Economics

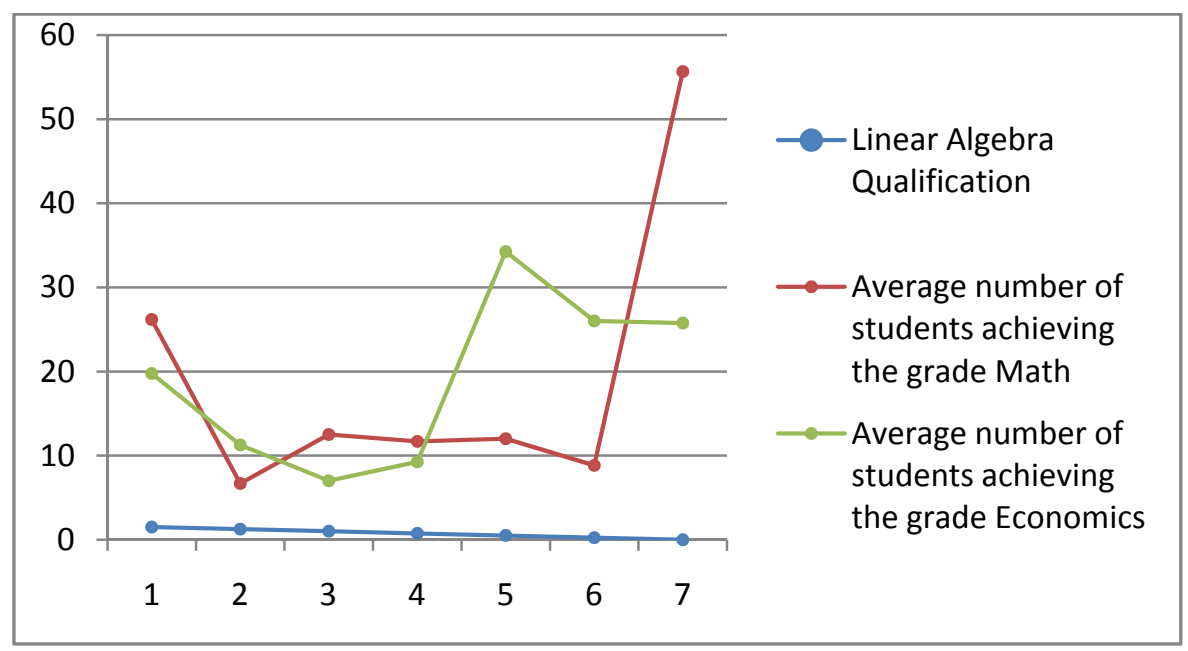


While the mathematical content questions receive more zeros in theory, it is also true that the economics questions focus their grades on low values, while the accepted ones are more commonly given in the mathematical content questions. We can assume that a student is more likely to answer something before a question of economic content, even if their responses are not always correct; on the other hand, questions of mathematical content deter students who do not understand them from the start.

Second, we went through the same process with the calculus test questions. We've also looked at a variety of questions that were posed on calculus exams and had numerical scores ranging from 0 to 1.75 points. We counted the average number of times the corresponding grade was given, and the results are collected in the table 4, which counts the average number of times the corresponding grade was given to the students.

Table 4: Average Number of Student with qualification

\begin{tabular}{|c|c|c|}
\hline Linear Algebra & \multicolumn{2}{|c|}{ Average number of students achieving the grade } \\
\hline Qualification & Math & Economics \\
\hline 0.00 & 43.60 & 56.67 \\
\hline 0.25 & 9.00 & 2.00 \\
\hline 0.50 & 24.00 & 9.67 \\
\hline 0.75 & 11.00 & 25.33 \\
\hline 1.00 & 14.80 & 12.00 \\
\hline 1.25 & 31.40 & 40.00 \\
\hline 1.50 & 32.75 & 18.00 \\
\hline 1.75 & 21.67 & 26.00 \\
\hline
\end{tabular}

Source: Survey Report

Figure 4: Graphical of Average Number of Student with qualification

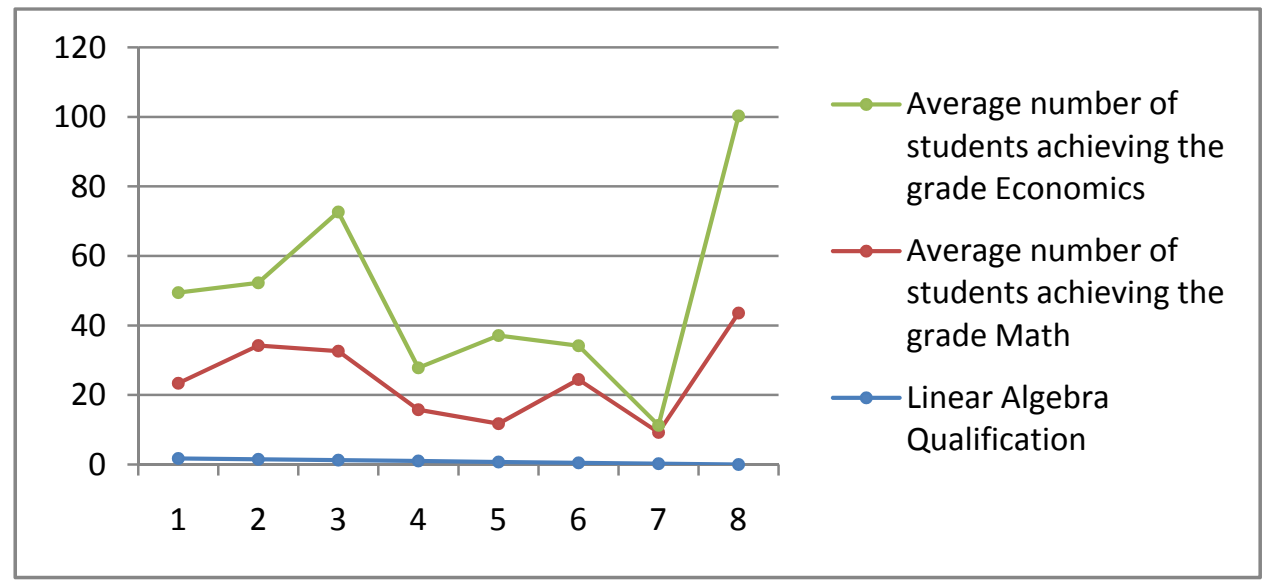


We see that now the results are reversed and that the students obtain a greater number of positive marks on the economic content questions. In linear algebra and calculus, there tend to be major variations in how students respond to questions with economic content. In those of linear algebra, the student may be shocked to find that, while not rejecting them, he achieves better results in economic content issues. In differential and integral calculus, this pattern is reversible.We may mention the following as explanatory factors for this fact:

In linear algebra, the modeling effort of the proposed exercise is much higher than that required in calculus questions. The techniques used in calculus are much simpler and do not require a strong effort to interpret the statement, unlike linear algebra, where the interpretation of the statements has a very important influence on the final results.

Linear algebra questions with mathematical content are more common since over the years they have been repeated systematically, also the degree of variation of the answers is much less than in calculus questions where, and although the student knows the type of question its specific resolution presents a greater degree of variation.

The student sees the mathematical-economics relationship much more in the calculation part, closer to economic theory. For their part, the examples of linear algebra are novel and their presence is not usual in other subjects of the business science degree.

The table 5 shows the evolution of the number of passed according to whether or not economic content questions predominated in the exam compared to mathematical content questions:

Table 5: Approved Percentages

\begin{tabular}{|c|c|c|}
\hline Percentage Approved & Algebra & Calculation \\
\hline Economics & $20.10 \%$ & $45.69 \%$ \\
\hline Math & $32.58 \%$ & $54.00 \%$ \\
\hline
\end{tabular}

Source: Survey Report

Figure 5: Graphs in Approved Percentages

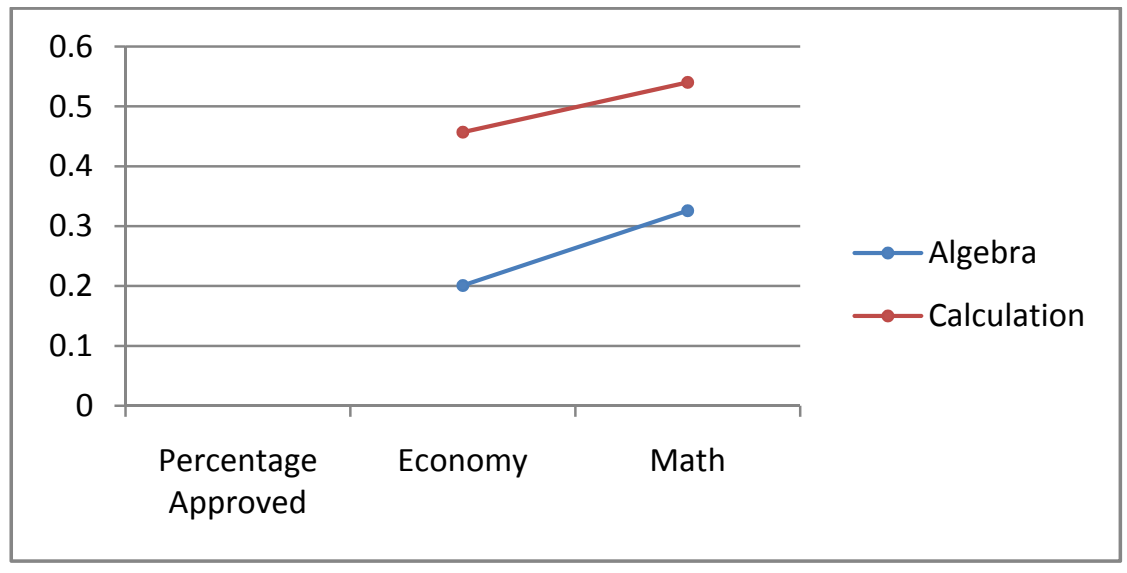


We can see that the performance statistics (the number of people who passed out of the total number of people who tried) show that the exams with the most questions with mathematical content (which account for more than half of the overall exam grade) have higher percentages than the exams with the most economic content.

We can see that the disparity is even greater in the case of algebra exams (12 points below), compared to calculus exams, where the difference does not exceed nine percentage points.

The overall disparity in success between the algebra and calculus exams can be explained by the fact that the algebra exam is the first they take in this subject (which corresponds to December), while the calculus exam is always taken after the algebra exam (corresponds to April). The percentage of students who take the algebra exam is greater than those who take the calculus exam, according to the student body's evolution.

\section{Conclusion}

According to the findings, the inclusion of economics in mathematics programs implies, in theory, a break from the student's planned conventional scheme and has an effect on exam results. The student, on the other hand, does not object to this format.

However, in comparison to differential and integral calculus partials, its negative effect appears to be much more important in linear algebra partials. This may be due to the greater effort of abstraction required by algebra versus the rather mechanistic nature of differential and integral calculus in the study of mathematics for economic sciences.

Given the simplicity of the basic support they provide for economic theory, the contents of differential and integral calculus are best included within the economy. Finally, students learn to apply elasticity, surplus, and marginalism concepts in a natural way, similar to how they apply other traditional calculus concepts. This explains why the effects of differential and integral calculus in mathematical and economic problems are nearly identical.

The economic content of linear algebra is focused on the application of linear relationship systems, especially linear relationship systems, to economics, which necessitates learning to perform abstraction and modeling processes, which our students may not have yet. They are trained, and it will take more effort. This is perhaps the most important factor in explaining the economic performance.

Nonetheless, we believe that the best course of action is and try to improve the students' ability to carry out these abstraction and modeling processes, since, while we might be able to do without them in linear algebra, they will be required in the final part of the topic, mathematics, where any explanation that does not involve improving their ability to interpret problem statements is doomed. 


\section{References}

Anderson, G., Goff, B. \&Tollison, R. (1986).The rise and (recent) decline of mathematical economics, History of Economics Society Bulletin 8, 44-48.

Arkhipov, A. J. (1999). Modern economic thinking: PhD Thesis Rostov-on-Don.

Bai, J. \&Perron, P. (1998), 'Estimating and testing linear models with multiple structural changes', Econometrics 66(1), 47-78.

Bai, J. \&Perron, P. (2003), 'Computation and analysis of multiple structural change models', Journal of Applied Econometrics 18(1), 1-22.

Bai, J. (1997). Estimating multiple breaks one at a time, Econometric Theory 13(01), 315-352.

Colander, D. (2005), The making of an economist redux, Middlebury College Working Paper Series 0531, Middlebury College, Department of Economics.

Debreu, G. (1984), 'Economic theory in mathematical mode', The American Economic Review74(3), 267-278.

Debreu, G. (1986), 'Theoretic models: Mathematical form and economic content', Econometrics $54(6), 1259-1270$.

Debreu, G. (1991), 'The mathematization of economic theory', The American Economic Review81(1), 1-7.Friedman, M. (1953). Essays in Positive Economics, Chicago: University of Chicago Press.

Ekwurzel, D. \& McMillan, J. (2001).'Economics online', Journal of Economic Literature (1), 39.

Goffe, W. L. \& Parks, R. P. (1997), 'The future information infrastructure in economics', The Journal of Economic Perspectives 11(3), 75-94.

Grubel, H. G. \& Boland, L. A. (1986), 'On the efficient use of mathematics in economics: Some theory, facts and results of an opinion survey', Kyklos 39(3), 419-42.

Hamermesh, D. S. \& Schmidt, P. (2003), 'The determinants of the econometric society fellows elections', Econometrica 71(1), 399-407.

Hodgson, G. (2004), 'On the problem of formalism in economics', Post-Autistic Economics Review 25(1).

Hodrick, R. Prescott, E. (2007), 'Journal of money, credit and banking', Post U.S. Business Cycles: An Empirical Investigation 29(1), $1-16$.

Jon V. (2004).The Mathematician. In R. Ayoub, Musings of the masters: an anthology ofmathematical reflections, pp. 169-185, MAA.

Katzner, D. (2003). 'Why mathematics in economics?', Journal of Post Keynesian Economics 25(4).

Kiyko, P. V. (2006).Mathematical modeling as a system-forming factor in the realization of Inter subject connections of mathematics and special disciplines in the training of future economists: PhD Thesis. Omsk: Omsk State Pedagogical University.

Krugman, P. (1998), 'Two cheers for formalism', The Economic Journal 108(451), 1829-1836.

Lawson, T. (2001), 'Two responses to the failings of modern economics: the instrumentalist and the realist', Review of Population and Social Policy 10, 155-181.mann, 
Lindbeck, A. (2001), The SverigsRiksbank Prize in Economic Sciences in Memory of Alfred Nobel 1969-2007 in The Nobel Prize: The First 100 Years, Imperial College Press and World Scientific Publishing Co. Pte. Ltd.

McCloskey, D., Katzner, D., Leamer, E. \& Solow, R. (1991), 'Has formalization in economics gone too far?',Methodus 3(1), 6-31.

Mirkowski, P. (1991), 'The when, the how and the why of mathematical expression in the history of economics analysis', The Journal of Economic Perspectives 5(1), 145-157

Neumann, R. P. (2004). Moral and Discursive geographies in the war for biodiversity in Africa.Political Geography 23(7):813-837.

Samuelson, P. (1954). Introduction: Mathematics in economics-no, no or yes, yes, yes?, The Reviewof Economics and Statistics 36(4), 359.

Sheila, C. D. (2003). Understanding the relationship between mathematics and economics, Journal of Post Keynesian Economics, 25:4, 547560, DOI: 10.1080/01603477.2003. 11051379 . 